\title{
EXPLORING THE USE OF SUEDE DYE ON LEATHER
}

\author{
J. O. B. Boahin' ${ }^{1}$, J. Adu-Agyem ${ }^{2}$ and Y. S. Peligah ${ }^{3}$ \\ ${ }^{1}$ Department of Integrated Rural Art and Industry, KNUST, Kumasi \\ ${ }^{2}$ Department of General Art Studies, KNUST, Kumasi \\ ${ }^{3}$ Tamale Polytechnic, Tamale.
}

\begin{abstract}
The indigenous leather tanners in Ghana lack access to variety in dyes and colourants, this limits the ability of their products to meet the demands of the market. Meanwhile, their livelihood highly depends on the sales of leather and leather artefacts. This study found it imperative to find alternate dyestuffs that are easily obtainable and comfortable to use by local tanners and leather users. The experiment on the use of suede dye on leather was done in three formats. In the first format, suede dye and salt were dissolved in warm water and a sheet of leather was immersed in the solution. In the second format, dye and alum were dissolved together in warm water after which leather was immersed in the solution. In the third experiment, two different colours were mixed separately with alum in warm water and used on the same leather, one after the other. In all cases the dyed leather was rinsed in cold water to remove excess dye and then dried under a shade. The resulting work did not bleed or stain, and was found to be light-fast. The experiments proved that suede dye could be used as a colourant for leather.
\end{abstract}

Keywords: Suede dye, Dyestuff, Tanners, Pelt, Leather.

\section{INTRODUCTION}

The need to improve on the indigenous art forms for national development has necessitated the exploration of existing local materials and technologies to improve upon them to meet contemporary needs of society. Leather has been defined by Reed (1972); Redmond (2007) and Taylor et al. (2009), as animal skin that has been chemically modified to produce a strong, flexible material that resists decay. It has also been further emphasized by Waterer (1966), Newman (1973), Sharphouse (1995) and Nguyen (2007) that almost all the world output of leather is produced from cattle hides and calfskins, goatskins kidskins, sheepskins and lambskins. Other hides and skins used include those of the horse, pig, kangaroo, deer, reptiles, seal, and walrus.

The indigenous Ghanaian tanners use the vegetable tanning technique. In this process, the tanning agent, which renders the skin immune to decay and prevents shrinkage is a substance known as tannin. Howes (1953) emphasizes that tannin is extracted from the bark, stem, fruit, and leaves of trees. Bagaruwa, 'grinded acacia pods' is the major domestic source of the tannin used by the Ghanaian indigenous leather industry.

Currently, the colour ranges used by the indigenous leather tanners are limited to brown, black 


\section{9}

and white. The popular, natural cream colour of leather is the basic colour that pelts assume before dyeing. The red dye is the most common of all the dyes and it is obtained by pounding guinea-corn leaves which is mixed with water and then leached to obtain the dye solution. Unfortunately, this dye bleeds and fades when exposed to sunlight. They also turn dark after they have been handled in the arm over a period of time. Plates 1, 2 and 3 below, illustrate the preparation of the dye from guinea-corn leaves and its application on leather as done by local tanners.

The researcher's desired to find alternate dyestuffs that are less expensive and can be obtained in different colours and also used on

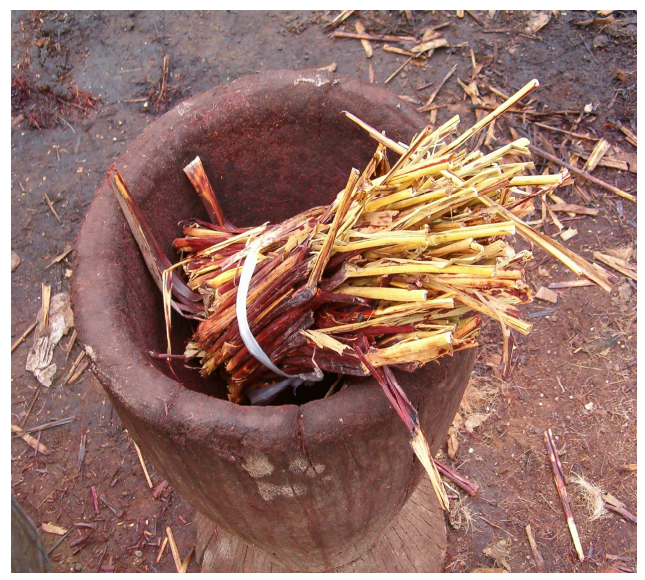

Plate 1: Guinea corn leaves

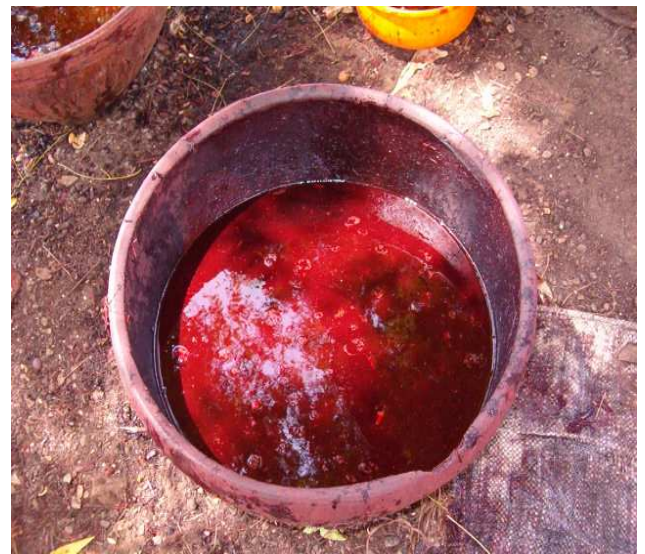

Plate 2: Extracted dyes after pounding

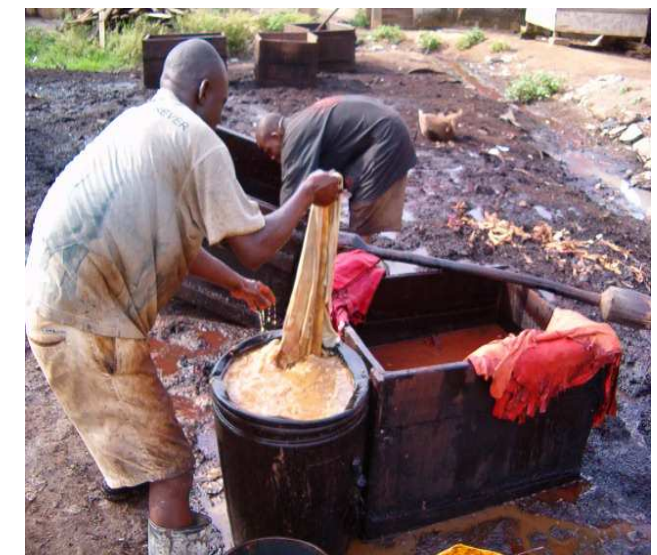

Plate 3: Workmen preparing leather for dyeing

leather without disturbing its surface quality. It is in the light of this that the use of 'suede dye' (sudee) a local dyestuff that is easily available and can be found in almost every market in Ghana was chosen for this research. Suede dye is a natural dye that is grounded and is obtained from mineral source. The choice of suede dye is further reinforced by the fact that the industry is largely indigenous based and there are no known alternate dyestuffs from which local tanners can obtain variety of colours to dye leather.

According to Allen (1971) and Lewin (2007), dyestuffs refer to any of a large group of chemicals almost exclusively organic in nature, used for the colouring of textiles, inks, food products, and other substances; basically every dye may be dissolved in some solvent to make it useful. O'Flaherty et al., (1962) have also asserted that dyestuffs ought to be capable of entering and colouring leather fibres or other substances. Suede dye is a dyestuff commonly used to stain leathers with napped finish, technically known as 'suede leather'. It is obtained in powdery form and known to be a staining substance which uses water as a vehicle and dissolves quickly in it. Therefore dyed articles always have to be protected from coming into contact with water or moisture, a situation which affects the comfort of using such articles.

Journal of Science and Technology @ KNUST August 2011 
The dyestuff is transparent and thinner than paint or coating, and it penetrates into the grain of material being dyed. The dye is known to have been used locally to dye raffia and straw; it is also known to bleed and stain easily. Suede dyestuff is not known in the local Ghanaian leather industry as a fast dye for dyeing leather, it therefore required the selection of appropriate mordants that could make it fast on leather. Mordant, improves the fastness of the dye against water, light and perspiration. The choice of mordant is very important as different mordants can change the final colour of dyes significantly.

\section{MATERIALS AND METHODS Selected Techniques}

The selected techniques used for the experiments were were 'Plain dyeing' and 'Marbling'.

\section{Experiment 1: Plain dyeing (Monochromatic Colours)}

Two different colours of suede dye: red and blue, were applied separately to two sheets of leather by following a common dyeing procedure as described below:

The leathers were dampened with clean water and each one was pounded for ten minutes in a mortar with a wooden pestle to loosen up the fibers. They became very soft and the fibers opened up to enable easy absorption of dyes.

One tablespoonful (10 gram) of red suede dye and six tablespoonfuls (60 gram) of alum (KAL (SO4)2.12H2O) were mixed with four litres of warm water in a plastic container in the first instance. Alum is a mordant in the suede dyeing process and it is very soluble in warm water. Afterwards, the pounded cream coloured sheet of leather was immersed in the dye solution and stirred for about five minutes; this allowed the dye solution to penetrate the fibres of the leather. It was left in the solution for about fifteen minutes. Thereafter the dyed leather was removed and left in a shade for ten minutes. It was then rinsed in clean water to clear the excess dye solution. The leather was pulled taut on a stretcher board and allowed to dry slowly in a shade.

A burnisher was used to rub over the surface of the dried leather to give it sheen and a soft, smooth surface value. The fluffy nature of the leather was achieved after the flesh side was rubbed gently with rough abrasive paper to achieve a regular surface. Finally, the leather was exposed to sunlight continuously for fourteen days to test its effect on the suede dyed leather against fading. This procedure was repeated with blue suede dye to test how different colours would behave by following similar experiment.

\section{Experiment 2:}

Following the procedure in experiment 1 , blue and green suede dyes were used to test how different colours would behave. Six tablespoonfuls of common salt (sodium chloride) was mixed with blue dye and warm water instead of alum for preparing the dye solution, after which a sheet of leather was immersed in it. The same method was repeated by using green suede dye.

\section{Experiment 3:}

The processes for preparing the dye solution for experiment one was used. However, in this instance, red and brown dye solutions were used. The leather was loosely and randomly crumpled and dyed in a red dye solution for about fifteen minutes and then allowed to dry. Some parts of the leather were tied with raffia before immersing it in a brown dye solution. After fifteen minutes, it was removed, rinsed in clean water and then dried in a shade. The dried dyed leather was burnished with the burnishing tool to give it a glossy effect (See plate 9).

\section{RESULTS AND DISCUSSION}

In experiment one, two different colours of suede dyes (red and blue) were used by following the common processes described above. The suede dye proved to be more effective for 


\section{$71 \quad$ Boahin et al.}

colouring leather. The two differently coloured pieces of leather produced were very bright. The colours were water-fast and did not bleed. After exposing them to sunlight for 90 days there was no evidence of change in the colours on any of the dyed leather, thus indicating that suede dye can withstand the strong tropical weather and sun experienced in Ghana.

The working process was very simple and time saving. The dye and chemicals used were not toxic as some other dyes. The dyes, which come in different colours, are inexpensive and are locally available. It was realized that the warm water makes it easier for fibers to loosen up to absorb the dye solution.

The alum also enabled the development of soft and pliable leather. Dyeing is achieved on both sides of the leather in a distinct manner that provides the leather worker the opportunity of deciding which side to use, either the grain side or the flesh side. If the flesh side is to be used the leather is termed suede leather as it is commonly known.

In experiment two, the common salt (Sodium chloride) and blue dye were used to prepare the dye solution instead of alum as used earlier in experiment one, and similar result was obtained as above, the same is said of experiment three, where following the same procedure, green was used. The dyeing substances did not stain the hands of the researcher on contact after it had dried under a shade.

The research has confirmed that suede dye could be used effectively as other known leather dyes to achieve a myriad effect on leather. It has resulted in obtaining a brand of suede dye that is permanent and can be used for changing the colour of leather articles. These dyes are guaranteed to penetrate leather, and to form a lasting colour which will not peel or crack. They are also excellent for use in the manufacturing or re-colouring of shoes, saddles, tack, belts, and purses, to mention a few.
Plates 4, 5 and 6 are illustrations of the results of suede-dyed leathers produced from the mixture of alum and suede dye. Plates 7 and 8 also illustrate leather dyed with the mixture of common salt (sodium chloride) and suede dye.

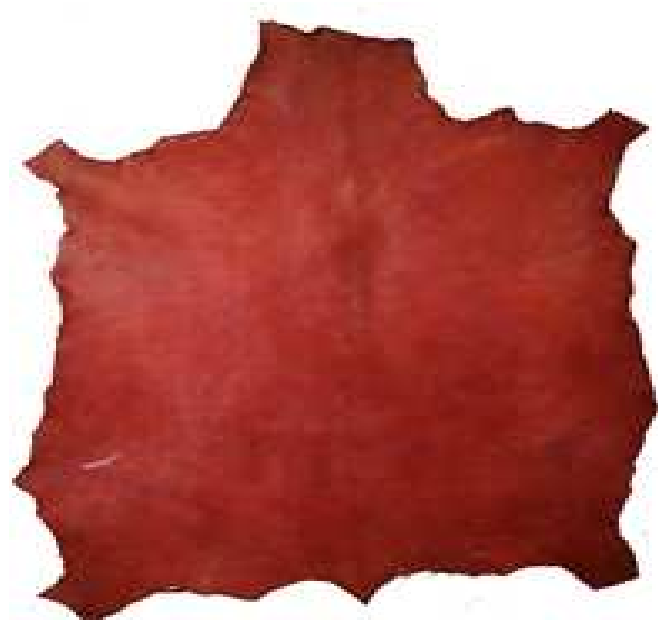

Plate 4: Grain side - red leather

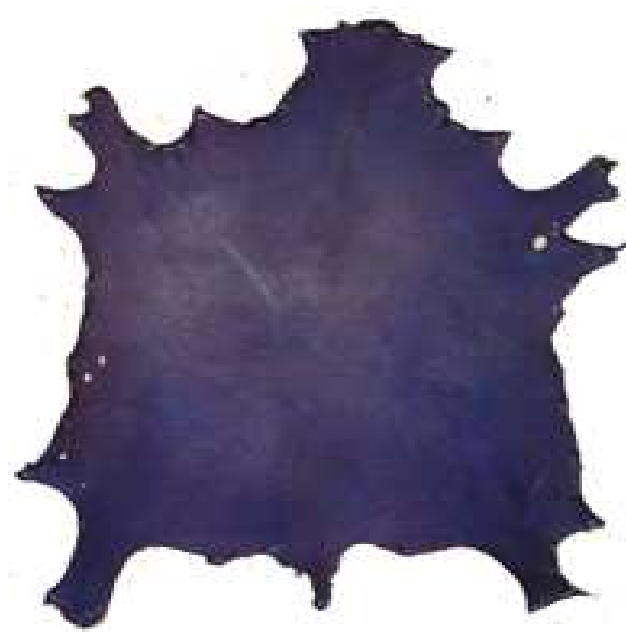

Plate 5: Grain side - blue dyed 


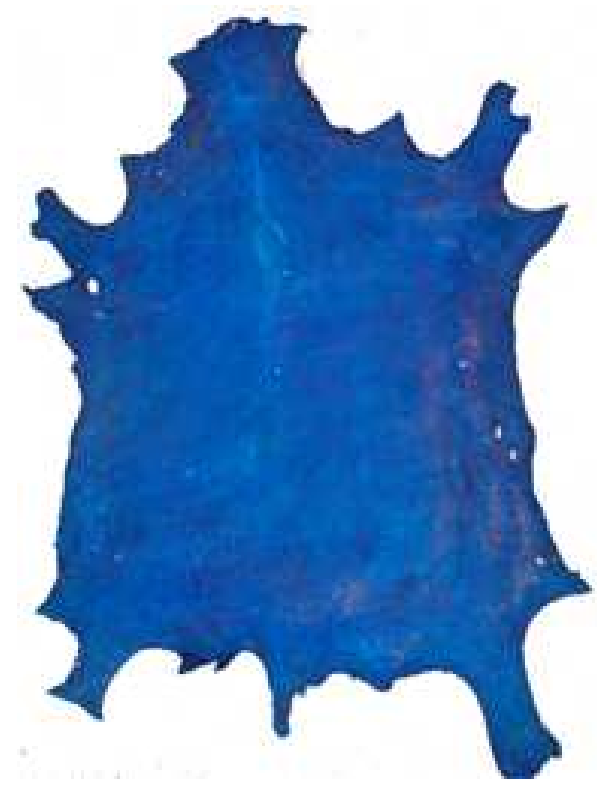

Plate 6: Flesh side - blue dyed

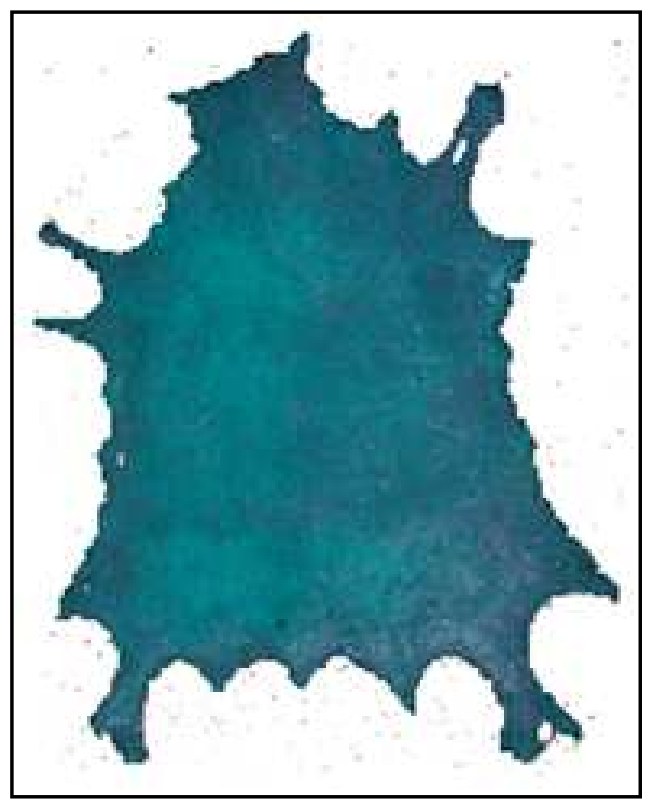

Plate 8: Flesh side - green dyed

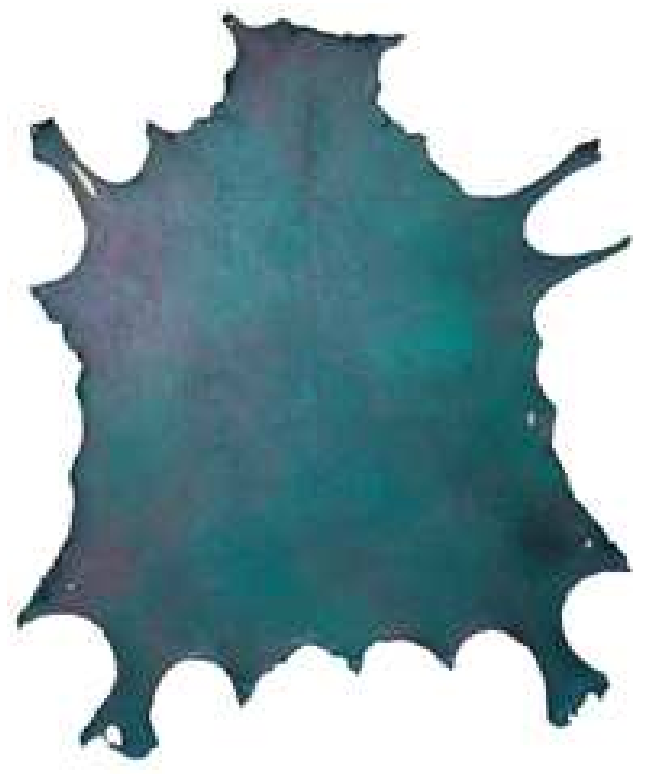

Plate 7: Grain side - green dyed

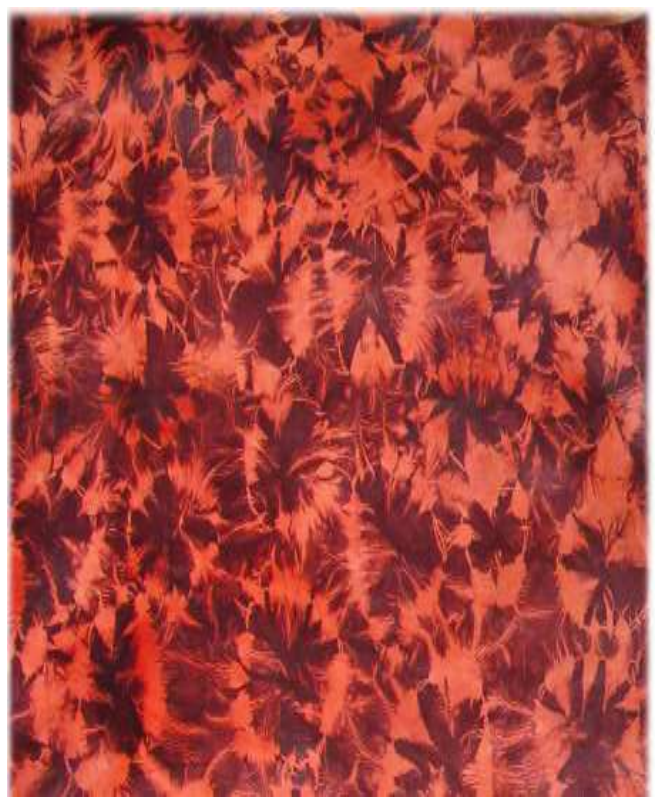

Plate 9: A sample showing the result of the tie-dye technique for dyeing leather 


\section{CONCLUSION}

The research explored the possibility of using suede dye a locally available dyestuff as colourants for leather; due to the limited range of colourants available to Ghanaian leatherworkers in Ghana. It revealed that by mixing suede dye and common salt (sodium chloride) or alum (Potassium alum), very brilliant and fast colouring could be achieved on leather. It also outlined very simple procedures for the ordinary leatherworker to apply the dye and its additives without much difficulty.

The research has made available to leatherworkers very simple, practical, and easy to follow formula by which suede dyes could be used to improve the aesthetic value of leather. Beside, it has also confirmed that the ordinary dyeing substance that is locally and easily available, and which is environmentally friendly, could be an equally good colouring agent for artisans to use.

Lastly, the use of suede dyes will help to add value to leather as students and craftsmen will be able to explore and develop more designs to produce variety of coloured leather artistic pieces for local consumption and for export.

\section{REFERENCES}

Allen R. L. M. (1971). Colour Chemistry Studies in Modern Chemistry; Apapa, Lagos Thomas Nelson (Nigeria) Ltd

Howes, F. N. (1953). Vegetable Tannin Materiials; London. Butterworths Scientific Publications.
Lewin, S. Z. (2007) "Dyestuffs." Microsoft Student 2007 [DVD]. Redmond, WA: Microsoft Corporation.

Newman, T. R. (1993). Leather as art and craft. London: Allen and Unwin

Nguyen, H. X. (2007) "Dyeing" Microsoft Student 2008 [DVD]. Redmond, WA; Microsoft Corporation

O'Flaherty, F., Roddy W.T. and Lollar R.M (1962). The Chemistry and Technology of Leather, Vol. III-Control of Leather Quality. Florida; Krieger Publishing Company.

Sharphouse, J. H. (1995). Leather Technician's Handbook, LPA 75th Anniversary Edition. Northampton, UK : Leather Producers' Association.

Taylor, A. M., Lee, J., Bumanlag, L.P., Cook P. H., Brown E. M. (2009). Treatment of Lowquality hides with fillers produced from sustainable Resources: Effect on properties of Leather, The Journal of American Leather Chemist Association, CIV (10): 325 $-327$

Waterer, J. W. (1966) Leather : in Life, Art and Industry. London: Faber and Faber.

Reed, R. (1972). Ancient Skins, Parchments and Leathers. New York: Seminar Press.

Redmond, W. A. (2007). 'Leather'. Microsoft ${ }^{\circledR}$ Student 2008 [DVD]: Microsoft Corporation. 